\title{
The Need of Pedestrian Footbridge to Promote Sustainable Living; Case Study: Footbridge Jln A Yani Pabelan, Kartasura
}

\author{
Yayi Arsandrie*, Anggita Danu Putra Prakoso \\ Study Programme of Architecture, Faculty of Engineering, Universitas Muhammadiyah Surakarta (U.M.S.), Indonesia
}

Received February 25, 2020; Revised June 24, 2020; Accepted July 7, 2020

Copyright $\odot 2020$ by authors, all rights reserved. Authors agree that this article remains permanently open access under the terms of the Creative Commons Attribution License 4.0 International License

\begin{abstract}
The purpose of the study is to support more sustainable behaviour, facilities should be provided for better pedestrian activities. One of the important facilities for pedestrians is a footbridge, which provides safety and comfort for its users. The increasing volume of vehicles in the city has made road traffic become extremely crowded. Pedestrian becomes the most vulnerable users of the road to get traffic accident, especially during rush hour. The footbridges are built to help people to cross the high traffic road and to reduce accident rates. This research was conducted to study the behaviour of people and to find the factors to increase the footbridge use. Methodology: Research was conducted on footbridge Jalan Ahmad Yani Pabelan Kartasura using observation and questionnaire methods. The observation was conducted to record the vehicle traffic and the footbridge area; meanwhile, questionnaires/interview were done to as many as 35 people who crossed by the footbridge surrounding and questionnaires were spread to 117 university students. Results: Research showed that the vehicles crossing by the road of Jalan Ahmad Yani Pabelan are significantly high, especially during the rush hours. The observation of the footbridge showed that it had fulfilled the minimum standard from the Ministry of Public Works; however, the intensity of footbridge usage is extremely less. Questionnaires to university students showed that as much as $84.6 \%$ of students prefer to use a motorcycle as daily transportation. Only $15.4 \%$ students use sustainable transportation, i.e: public transportation $(6.8 \%)$, bicycle $(2.6 \%)$, or walking $(6 \%)$. The pedestrian footbridge usage is very low; it is only $0.85 \%$ who often use footbridge on Jalan Ahmad Yani Pabelan, and $11.97 \%$ use it for 1 to 5 times. Research showed that there is no significant gender preference. The highlighted factors which attract pedestrian attention are the safety, distance and aesthetical value of footbridge.
\end{abstract}

Keywords Pedestrian, Footbridge, Sustainable, Living

\section{Introduction}

Walking is one of the recommended activities for sustainable living. Not only does it supports the energy saving, but also is beneficial for human health. Walking is also more effective and efficient, especially for a short distance. In some places in developing countries, walking activity is quite large, such as in India (Tabish\&Khumar, 2017) and Jordan (Abojaradeh, 2013).

One of the important pedestrian facilities is pedestrian bridges. According to Demirarslan (2017), pedestrian bridges could be built from different structures and constructed by using various materials for connecting people from one place to another by walking across them. The pedestrian footbridges are supposed to support the landscape and urban design by their aesthetic structures. Demirarslan (2017) has classified pedestrian bridges into some categories, such as: in accordance with the relation to the ground (for example over ground bridges/footbridge, underground bridges/tunnel, floating bridges and the bridges which stand between two structures), with the materials (such as stone, wooden, steel, iron, reinforced concrete), and with their functions (for example bridges for pedestrian-only or for pedestrian and vehicles). Based on these categories, therefore, the term of the pedestrian footbridge is used in this research.

In accordance with the basic function of the pedestrian footbridges, they are especially needed in the place where there are crowded traffics or natural creations which separate two places. The increasing number of vehicles every day in the big cities is causing pedestrians to be the 
most vulnerable to get a traffic accident. The absence of adequate pedestrian lines, the provision of facilities that are not in the best performance had caused the footbridges to tend not to be used by pedestrians in the majority. This also happens in Jordan; although $50 \%$ of children in Jordan walk to school, more than $60 \%$ of pedestrians choose not to use footbridge for a variety of reasons (Abojaradeh, 2013). Meanwhile, in several large cities as in Jakarta, a pedestrian footbridge is also used by motorcycle because the drivers try to avoid the long-distance caused by railway tracks. The pedestrian footbridge dysfunction and usage are the main reasons of this research to be conducted. The objectives of this research are to study the use of footbridge on Jalan A Yani Pabelan Kartasura as a facility for pedestrians and the significant factors to be concerned.

\section{Method}

This research takes a case study on footbridge located on Jalan Ahmad Yani Pabelan Kartasura, approximately five hundred meters from University of Muhammadiyah
Surakarta University (U.M.S.) Campus, as Figure 1. The research was conducted by using several methods aimed to obtain traffic flow, pedestrian footbridge physical data, as well as pedestrian behaviours. Data of traffic flow was collected by video recording; the physical condition of the footbridge was measured and observes, as well as interviews and questionnaires were conducted to pedestrian people and university students.

\section{Observation}

Observations were made to observe the following conditions:

1. The observation was made by video recording of the traffic flow conditions on Jalan Ahmad Yani Pabelan Kartasura to record the number and type of vehicles that pass, especially during rush hour.

2. Observations were also made on the physical condition of the pedestrian footbridge which located nearby U.M.S. campus to match the Minister of Public Works Standards.

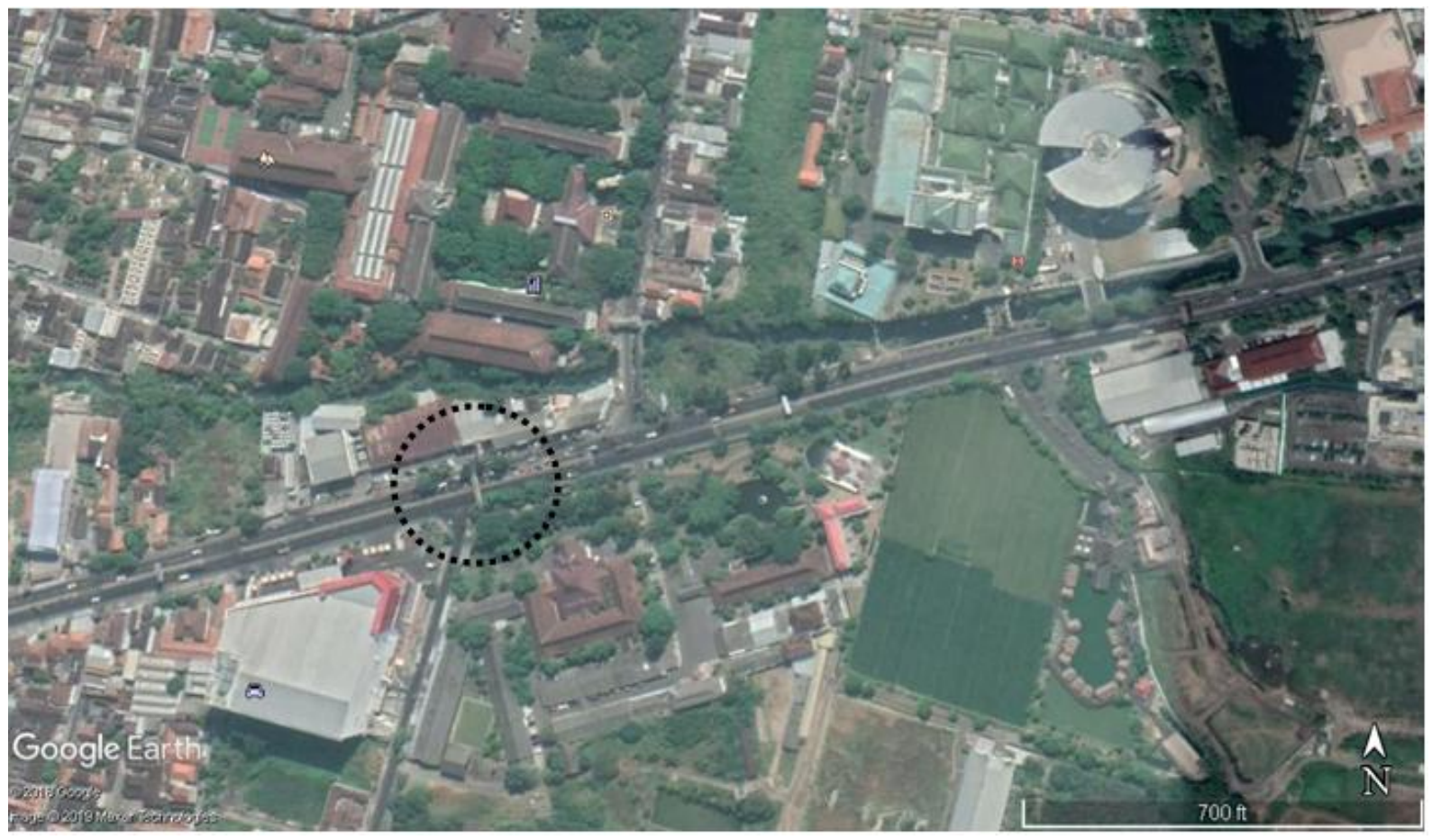

(Source: www. GoogleEarth, 2019)

Figure 1. Location of pedestrian bridge Jalan Ahmad Yani Pabelan Kartasura 


\section{Interview/Questionnaires}

Interviews were conducted to the pedestrian people who pass the footbridge area. Meanwhile, questionnaires were spread to U.M.S. students with the following conditions:

1. Interviews were held to 35 pedestrians who pass around the footbridge randomly, but only 25 people were willing to answer the questions. Interviews with pedestrian communities contain questions about: the intensity of using footbridge and zebra cross, as well as their experience of using the footbridge. Respondents were also asked about their opinions and suggestions for the sustainability of the footbridge at Jalan Ahmad Yani Pabelan Kartasura.

2. Questionnaires were distributed to university students of Architecture Study Program at the Universitas Muhammadiyah Surakarta (U.M.S.), and 117 students were willing to fill the questionnaires. The questionnaires included the following questions: the origin of students, length of stay in Surakarta, modes of transportation they used, the experience of using pedestrian footbridges on Jalan Ahmad Yani Pabelan Kartasura, as well as respondents' assessments of the footbridge.

\section{Results and Discussion}

\section{Observation of the Traffic Vehicles}

The results of the video recording of traffic density on Jalan Ahmad Yani Pabelan Kartasura (in the area around the U.M.S. Campus) show that at 6:30 a.m. to 7:00 a.m. W.I.B. is the heaviest traffic of light vehicles such as city transportation, private cars and pickups; the total of 135 small vehicles are recorded passing on the road, see Table 1. Meanwhile, at 10:00 to 16:30 W.I.B., the type of large bus vehicle passes 14-18 times per 30 minutes, trucks 3-6 times per 30 minutes, trailers 1-2 times per 30 minutes. Based on the results of observations and calculation of traffic rates, the amount of transportation that passes through Jalan Ahmad Yani is very high; 35 vehicles/day for 30 minutes at 6:30 a.m. to 7:00 a.m. This shows that footbridge is needed.

\section{Observation to the Footbridge on Jalan Ahmad Yani Pabelan Kartasura}

Based on the physical measurement and observation data of pedestrian footbridge around U.M.S. Campus, it has the conditions as shown in Table 2.

Table 1. Vehicles traffic on Jalan Ahmad Yani Pabelan during rush hours

\begin{tabular}{|c|c|c|c|c|c|c|c|c|c|}
\hline \multirow{2}{*}{$\begin{array}{c}\text { Vehicle Type } \\
\text { Time }\end{array}$} & \multirow{2}{*}{$\begin{array}{c}\text { LV: Light Vehicles } \\
\text { Public } \\
\text { Transportation, } \\
\text { sedan, jeep, } \\
\text { private cars, pick } \\
\text { up cars }\end{array}$} & \multicolumn{8}{|c|}{ H.V.: Heavy Vehicles } \\
\hline & & $\begin{array}{c}\text { Bus } \\
\text { 1.2L } \\
\text { Mikro } \\
\text { Bus }\end{array}$ & $\begin{array}{c}\text { Bus } \\
\text { 1.2L Big } \\
\text { bus }\end{array}$ & $\begin{array}{c}1.2 \mathrm{~L} \\
\text { Truck }\end{array}$ & $\begin{array}{c}1.2 \mathrm{H} \\
\text { Truck }\end{array}$ & $\begin{array}{c}1.22 \\
\text { Truck }\end{array}$ & $\begin{array}{c}1.2+22 \\
\text { Trailer }\end{array}$ & $\begin{array}{c}1.2-2 \\
\text { Trailer }\end{array}$ & $\begin{array}{c}\text { 1.2-2.2 } \\
\text { Trailer }\end{array}$ \\
\hline $06.30-07.00$ & 135 & - & 16 & 6 & - & 4 & - & - & - \\
\hline $10.00-10.30$ & 90 & - & 15 & 5 & 4 & 6 & 2 & 3 & - \\
\hline $14.00-14.30$ & 95 & - & 14 & 3 & - & 3 & 2 & - & 3 \\
\hline $16.00-16.30$ & 120 & - & 18 & 3 & 5 & 5 & 2 & 4 & 6 \\
\hline
\end{tabular}

Table 2. Pedestrian footbridge on Jalan Ahmad Yani Pabelan Kartasura

\begin{tabular}{|c|c|c|c|}
\hline No & Measured Aspects & Standard & Footbridge Pabelan Kartasura \\
\hline 1 & Height of steps & $15-21.5 \mathrm{~cm}$ & $20 \mathrm{~cm}$ \\
\hline 2 & Minimum pedestrian width & $2 \mathrm{~m}$ & $2 \mathrm{~m}$ \\
\hline 3 & Stair height & $1.35 \mathrm{~m}$ & $1.3 \mathrm{~m}$ \\
\hline 4 & $\begin{array}{c}\text { The layer of the structural pole on the } \\
\text { high-speed highway }\end{array}$ & $12 \times 12 \mathrm{~mm}$ with min. height $3 \mathrm{~m}$ & $12 \times 12 \mathrm{~mm}$ with min. height $3 \mathrm{~m}$ \\
\hline 5 & Footbridge length & $>40 \mathrm{~m}$ heat protection apply & $>40 \mathrm{~m}$ heat protection apply \\
\hline 6 & Location of footbridge steps & Outside the sidewalk & Outside the sidewalk \\
\hline 7 & Standing width of steps & $21.5-30.5 \mathrm{~cm}$ & $30 \mathrm{~cm}$ \\
\hline
\end{tabular}




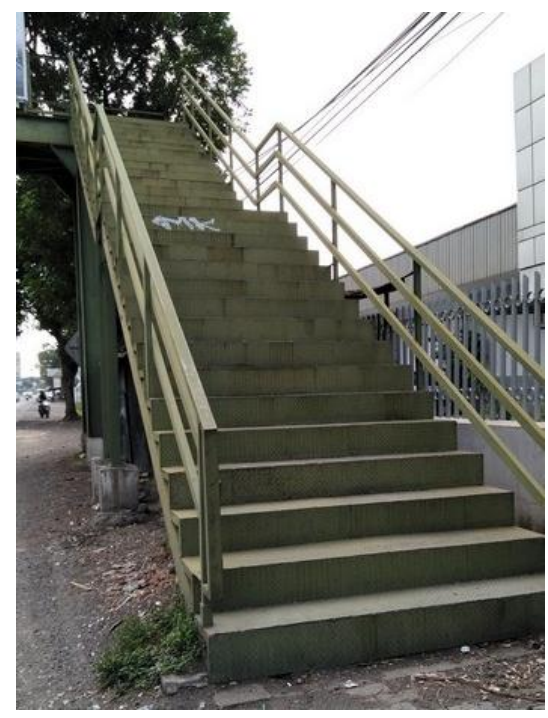

(a)

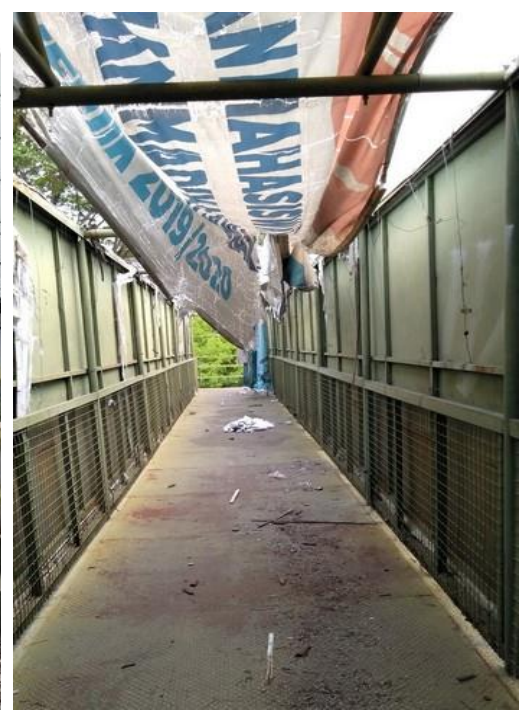

(b)

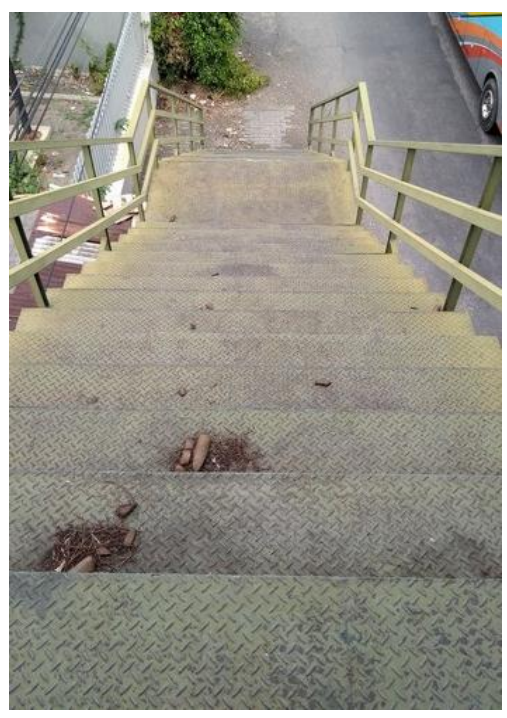

(c)

(a) height of footbridge steps (b) footbridge walking path (c) footbridge steps viewed from upstairs

Figure 2. Pedestrian footbridge on Jln A. Yani Pabelan Kartasura

The footbridge condition can be seen in Figure 2. The physical examination and measurement results of the footbridge based on a comparison with the Standard of the Minister of Public Works indicate that the footbridge of Jalan Ahmad Yani Pabelan has met the standard.

Meanwhile, the results of physical observations of the structure, aesthetics, safety impression and cleanliness quality of the crossing bridge, as well as connectivity with the pedestrian path show the following data:

1. Structure: floors made of aluminium plates begin to corrode and porous because there is no roof cover to protect the footbridge from rain and sun exposure;

2. Aesthetics: the bridge does not look attractive because it is used as a media for advertising (see Figure 3) so it does not have access for users to get a view from the footbridge or from the road below. Besides, the footbridge also does not have an architecturally attractive design;

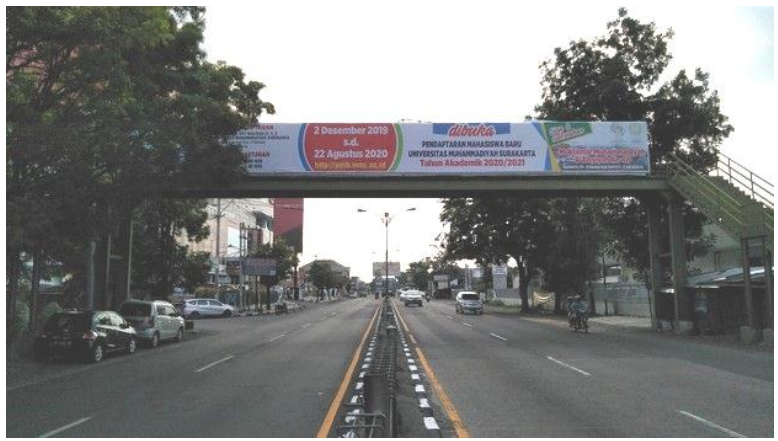

Figure 3. Pedestrian footbridge viewed from U.M.S. Campus direction
3. The impression of security: the impression of security lacks because the footbridge is massively closed and there is no lighting at night so that it can lead to criminal acts;

4. Quality of cleanliness: the condition of the pedestrian footbridge has a lot of garbage and smells bad;

5. Pedestrian connectivity: there is no adequate pedestrian path to connect with the footbridge; there is no distance or boundary between the pedestrian lane and the motor vehicles lane.

\section{Interview to the Pedestrian People Who Pass on the Footbridge Road Area}

The interview was conducted on 8-29 March 2018. The questionnaire was distributed to 35 people who were around the pedestrian footbridge on Jalan Ahmad Yani Pabelan Kartasura, but only 20 people were willing to answer the questions. This pedestrian interview produces data as can be seen in Figure 4 to Figure 8 .

The effectiveness of the pedestrian footbridge usage can be seen from the extent to which the community uses and utilizes footbridge as a crossing facility. Based on the interview data, it is known that most pedestrians rarely use footbridge (90\%); only $10 \%$ of respondents often use footbridge as can be seen in Figure 4. Pedestrian respondents prefer to cross over the zebra cross which located 50 meters from the footbridge than using the footbridge to cross the road; only $25 \%$ of them choose to cross using the footbridge due to safety, see Figure 5. 


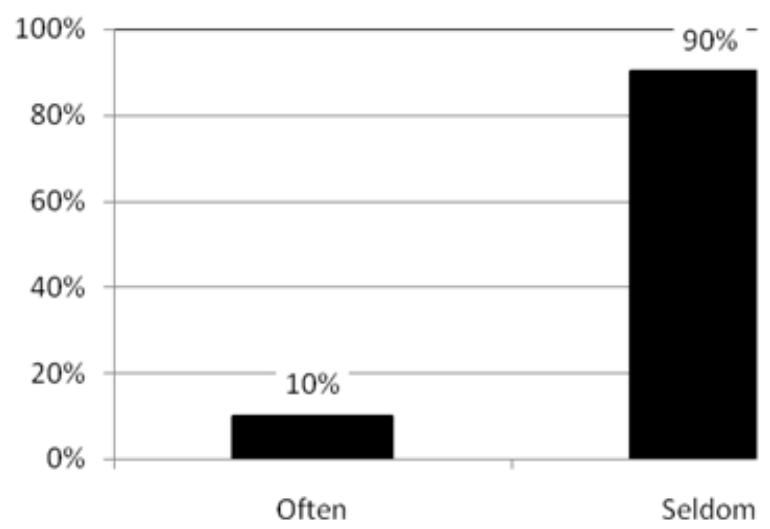

Figure 4. Footbridge usage on Jalan Ahmad Yani Pabelan Kartasura

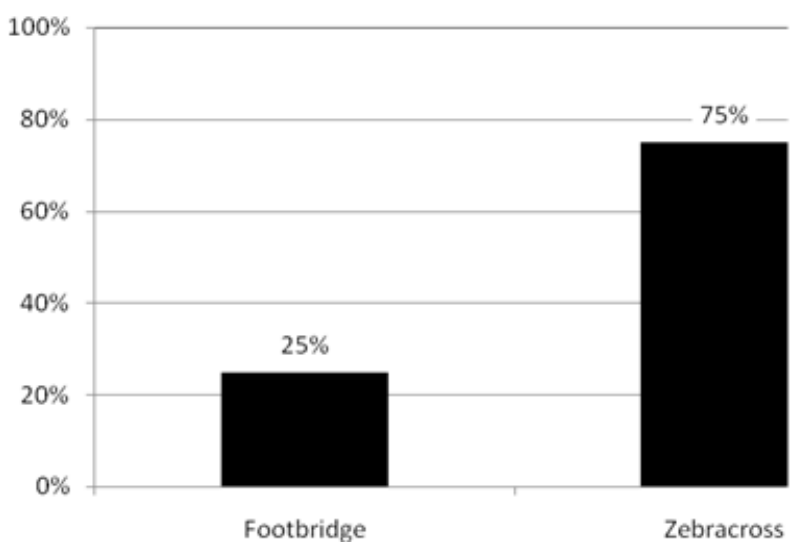

Figure 5. Pedestrian preference of footbridge and zebra cross usage on Jalan Ahmad Yani Pabelan Kartasura

Meanwhile, the majority of respondents (75\%) prefer to cross by using zebra cross than footbridge (see Figure 5). Those respondents who prefer to use zebra cross stated that the consideration of using zebra cross was based on the closer distance $(50 \%)$, too tired to cross through the footbridge $(20 \%)$, and they were accustomed to using zebra cross $(20 \%)$, and another $10 \%$ said that they did not see the pedestrian footbridge. In addition to these reasons, respondents were also concerned about the occurrence of crimes on the pedestrian footbridge such as pickpocket or other potential criminal acts.

The footbridge comfort is also lacking, which can be seen from the respondents' answers; $75 \%$ of respondents said that the footbridge was uncomfortable, see Figure 6. However, the data in Figure 7 showed that some $40 \%$ of pedestrians recognized that the footbridge was vital. This percentage is higher among other opinions that footbridge is essential, less important or not necessary to exist, with a rate of $30 \%, 20 \%$, and $10 \%$ respectively, seen Figure 7.

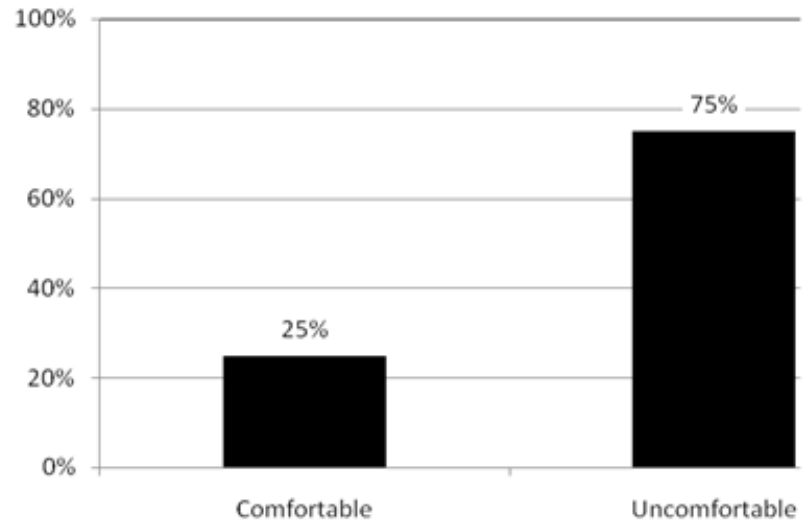

Figure 6. Pedestrian respondents on footbridge comfort

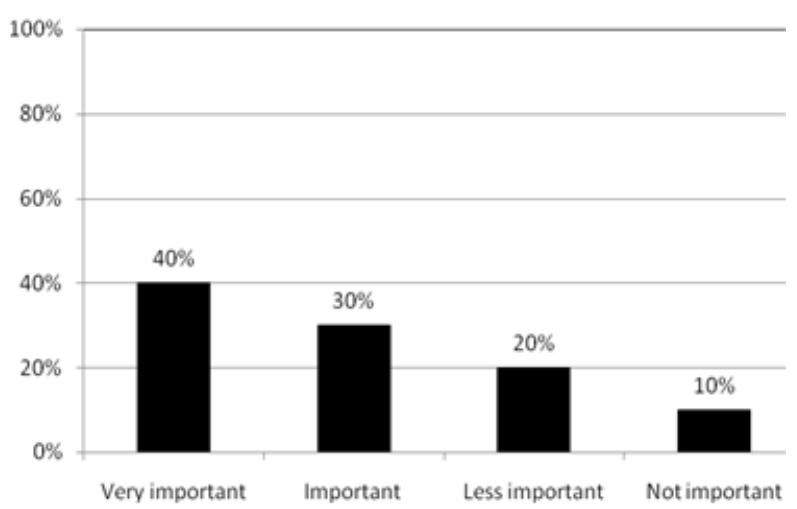

Figure 7. Pedestrian responses to the need for footbridge

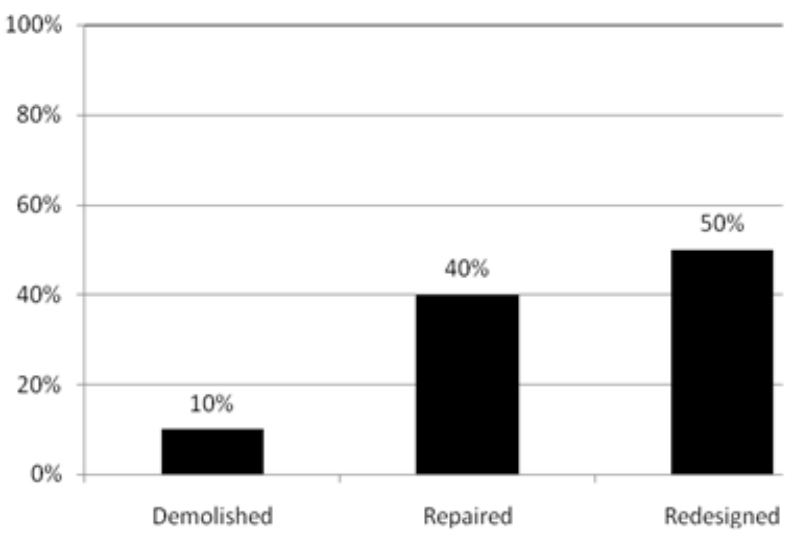

Figure 8. Pedestrian suggestions to the footbridge on Jalan Ahmad Yani Pabelan Kartasura

Based on the condition of the pedestrian footbridge on Jalan Ahmad Yani Pabelan Kartasura, only 10\% thought that the footbridge should be demolished, $40 \%$ respondents suggested to repair, and $50 \%$ recommended the pedestrian footbridge be redesigned. 


\section{Questionnaires to the University Students of U.M.S. about the Footbridge on Jalan Ahmad Yani Pabelan Kartasura}

The questionnaires were distributed to the university students of Architecture Study Program, Faculty of Engineering Universitas Muhammadiyah Surakarta on 16-21 October 2019. The surveys were distributed to 117 UMS students, consisting of 67 male and 50 female student respondents. A total of 23 students come from Surakarta, while 97 students come from outside of Surakarta City; they have been living in Surakarta City for about 2.6 years.

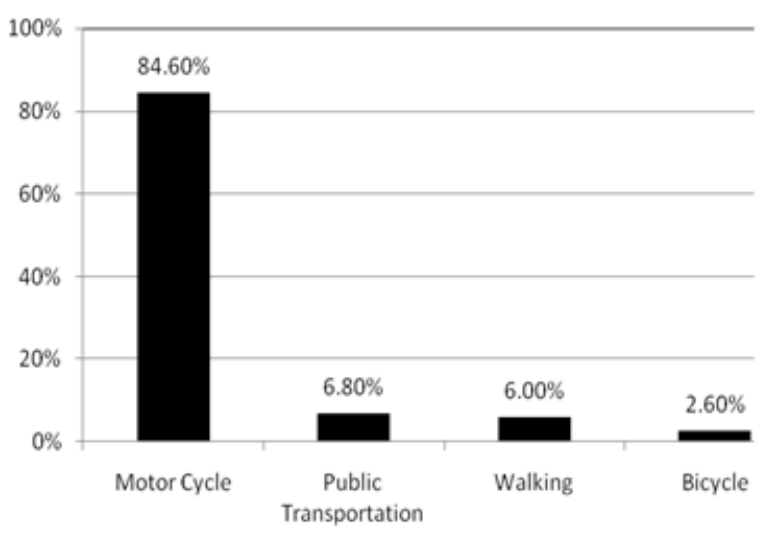

Figure 9. Transportation used by university student respondents

Based on the questionnaire, it was found that the majority of student respondents (84.6\%) used motorcycles as their mode of transportation. Not many students used sustainable transport, such as public transportation, bicycles, or walking, where the percentage was tiny, only $6.8 \%, 2.6 \%$, and $6 \%$ respectively, seen Figure 9. This behaviour certainly does not support sustainable living.

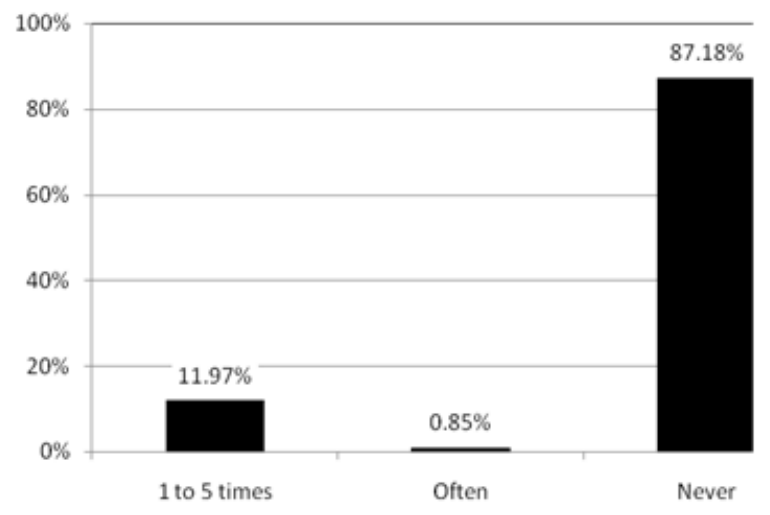

Figure 10. Pedestrian footbridge usage

A large number of student respondents had never used pedestrian footbridges (87.18\%). Only $11.97 \%$ of respondents had used the pedestrian footbridge for 1-5 times. Meanwhile, only one respondent $(0.85 \%)$ often used pedestrian footbridges, seen in Figure 10. This is not in accordance with research conducted by Rizati, Ishak \& Endut (2013) which stated that the intensity of footbridge use in school and residential environments tends to be higher compared with the use of footbridge in the business or amenity area. One important aspect that might be influential in this case is due to the distance of the footbridge which is far from the place of interest (Rizati, Ishak \& Endut, 2013), in this case, the location of U.M.S. Campus. Moreover, it can be figured out from Figure 9 that most of the U.M.S. students prefer to ride a motorcycle to go to campus as their primary transportation mode. Some reasons which cause them to choose motorcycle as their daily transportation are: 1) nowadays they can have motorcycles easily by loan from the leasing, 2) it will be faster to arrive to their destination compare to go on foot, and 3) the public facilities such as pedestrian street, shelter and pedestrian footbridge have not provided properly.

This study did not show a certain gender tendency in the use of footbridge as the findings in previous studies conducted by Abojaradeh (2013). That study found that women use footbridge more than men, and children tend to use it more than adults. By considering the main function of the pedestrian footbridge, the design of footbridges should allow all groups of people to access, including disabled people, elderly people, women and children. Therefore, the steps and ramp of the bridges should be standardized, suitable and safe for all users.

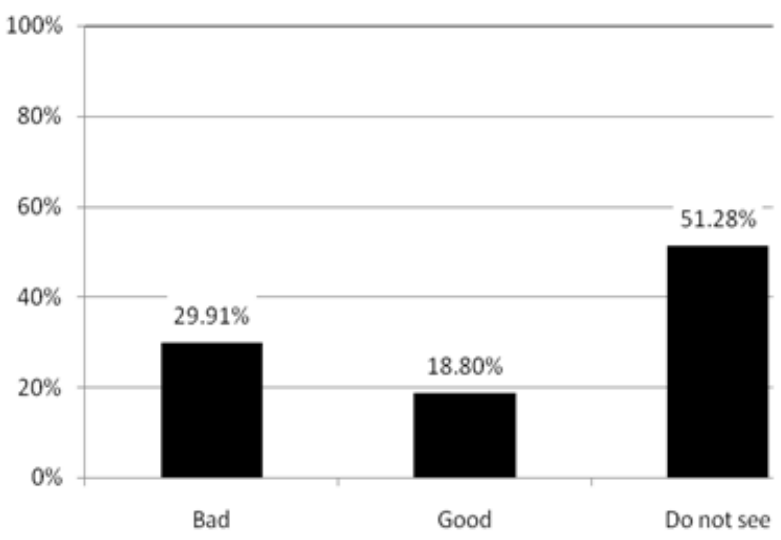

Figure 11. Student respondent's opinion to the pedestrian footbridge

Questions related to the opinion given by students to the footbridge show that more than $50 \%$ of respondents stated that they did not see the existence of a pedestrian bridge $(51.28 \%)$. Only $18.8 \%$ gave a good opinion of pedestrian footbridges, seen in Figure 11. This is in line with the answers of pedestrian respondents who crossed the road on Jalan Ahmad Yani Pabelan Kartasura, where some of them also said they did not see the existence of the pedestrian footbridge.

The majority of respondents gave the impression of the pedestrian footbridge on safety $(45.30 \%)$ and convenience distance $(41.88 \%$ ), while only $9.40 \%$ giving a rate of the aesthetical factor of the pedestrian footbridge on Jalan Ahmad Yani Pabelan Kartasura. The safety factor is the most important thing in a footbridge, both the safety of access to the footbridge and safety while passing on the 
footbridge. Other pedestrian facilities such as pedestrian tracks must also be connected properly and safely from motorcycles and other heavy vehicles tracks to create safety and comfort for pedestrians. Other factors such as ease of access (height of stairs and footbridge distance) must be concerned in footbridge design so that it can be accessed by all groups of people without exception, including elderly and children. Another aspect that is no less important is the aesthetical factor of the footbridge appearance. The architectural value of the footbridge's appearance becomes an important aspect to encourage more pedestrians to use footbridge to cross the road in order to reduce the number of traffic accidents and create a more comfortable environment and support environmental sustainability.

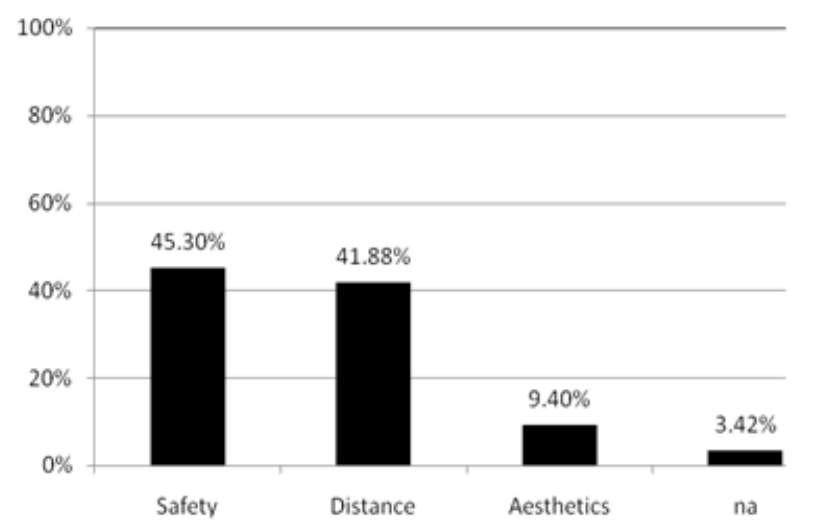

Figure 12. Respondent's impression about the pedestrian footbridge

\section{Conclusions}

Research showed that the vehicles traffic crossing by the road of Jalan Ahmad Yani Pabelan was significantly high, especially during the rush hours. This is caused by the extremely intensity of motorcycles and private vehicles usage, besides heavy traffic at the main road. Questionnaires to university students showed that as much as $84.6 \%$ students prefer to use motorcycle as daily transportation. Only $15.4 \%$ students use sustainable transportation, i.e: public transportation $(6.8 \%)$, bicycle $(2.6 \%)$, or walking (6\%). The observation of the footbridge showed that it has fulfilled the minimum standard from the Ministry of Public Work; however, the intensity of footbridge usage is extremely less. The pedestrian footbridge usage is very low; interview to pedestrian people showed that only $10 \%$ of respondents often use footbridge. Questionnaires to U.M.S. students showed that it is only $0.85 \%$ who often use footbridge on Jalan Ahmad Yani Pabelan and $11.97 \%$ use it for 1 to 5 times. Research showed that there is no significant preference related to gender which is more likely to use the pedestrian footbridge. The highlighted factors which attract pedestrian attention are the safety, distance, and aesthetical value of footbridge.
This research shows that the presence of the pedestrian footbridge on Jalan Ahmad Yani Pabelan Kartasura is necessary due to the busy traffic flow conditions especially during peak hours. Regarding standards from the Ministry of Public Works, this pedestrian footbridge has been able to meet the required criteria. However, there are other values needed to increase the use of footbridge in the public space. The U.M.S. student group is one of the potentials in driving a program of environmental and sustainable living. Unfortunately, most U.M.S. students are not interested in switching to using greener modes of transportation because the facilities are not yet adequate.

Three factors to consider in the pedestrian footbridge design are:

(1) Safety factor; this factor is the reason why footbridge needs to be provided, namely to reduce the number of traffic accidents. However, due to lack of planning, the safety factor is the reason why pedestrians do not choose to use footbridge, which is security from fear of possible criminal acts at the footbridge;

(2) Distance factor; another reason why pedestrians prefer to use zebra cross than footbridge is due to the ease and short distance. This is very important to highlight. A more human footbridge design with continuous connectivity between pedestrian lines makes it easy for pedestrians to travel. In addition, the height of the stairs that are not too steep will help pedestrian to travel easily without feeling tired. Consideration to the special group users such as the elderly and children need to give special attention so that the pedestrian footbridge can provide access for all;

(3) The aesthetical factor; although recently some footbridge designs have been built in big cities, however there are still many who haven't. The more attractive design of pedestrian footbridge will encourage people to switch to the healthier lifestyles by using green transportation or walking. Besides providing higher comfort, beautiful footbridge design will be an important part to create sustainable city.

\section{REFERENCES}

[1] Abojaradeh, M. (2013). Evaluation of pedestrian bridges and pedestrian safety in Jordan. Civil and Environmental Research, 3, No. 1. ISSN 2222-1719 (Paper) ISSN 2222-2863 (Online).

[2] Public Works Department, (1999). Pedoman perencanaan jalur pejalan kaki pada jalan umum No. 032/T/BM/1999, Dirjen Bina Marga, Jakarta.

[3] Public Works Department, (1995). Tata cara perencanaan jembatan penyeberangan pejalan kaki di perkotaan No. 027/T/Bt/1995, Dirjen Bina Marga, Jakarta.

[4] Demirarslan, D., (2017). Pedestrian Bridges and Passages in 
Terms of Space Design, IJASOS-International e-Journal of Advances in Social Sciences, Vol. III, Issue 7, April.

[5] Directorate General of Highways (1992). Pedoman Teknik, Standar perencanaan geometrik jalan kota, Jakarta.

[6] Directorate General of Highways (1992). Pedoman Teknik, Standar spesifikasi trotoar, Jakarta.

[7] Department of Transport Highway and Traffic, Design considerations for pelican and zebra crossing, TA 28/87.

[8] Department of Transport Highway and Traffic, Design considerations for pelican and zebra crossing, TA 52/87.

[9] Heinrich, H. Ch, (1990). Behavioural changes in context of traffic safety. I.A.T.S.S. Research, 14 No. 1, Tokyo.

[10] Rizati, H., Ishak, S.Z., \& Endut, I.R. (2013). The utilization rates of pedestrian bridges in Malaysia. IEEE Business
Engineering and Industrial Application Colloquium (B.E.I.A.C.)

[11] Hasan, R., \& Napiah, M. (2014). The effect of structure and street characteristics on the footbridge usage, Journal of Applied Science and Agriculture, 9 (21), 52-59.

[12] R. Hasan \& Napiah, M. (2017). Utilization of footbridges: influential factors and improvement proposal. Advances in Transportation Studies: an international journal section A 43.

[13] Tabish, S. \& Kumar, M. (2017). Research paper on study of pedestrian crossing behavior, analysis at intersection. International Journal of Latest Research in Science and Technology, Vol. 6, Issue 4: 43-47.

[14] Umar, I.K., Bashir,S., Alfanda, A.M. \& Farouk, A.I.B.B. (2019). Pedestrian's utilizations of footbridge in Kano-Nigeria. A.L.K.U. Journal of Science, 1(1), 33-39. 